\title{
Increasing Rural Electrification through Connection Campaigns*
}

\author{
Brian Blankenship \\ Ryan Kennedy \\ University of Miami \\ University of Houston \\ Aseem Mahajan \\ Harvard University \\ Jason Chun Yu Wong \\ Johannes Urpelainen \\ London School of Economics \\ Johns Hopkins SAIS
}

January 21, 2020

\begin{abstract}
To reach the United Nations Sustainable Development Goal of universal household electrification by 2030, developing countries are spending billions of dollars to expand access. India, for example, recently undertook an audacious expansion plan which aimed to electrify every household by December 2018. However, there is little academic study of strategies to increase electrification rates. We argue that significant transaction costs inhibit household applications for connections. As evidence, we report the results of a randomized controlled trial (in 200 communities and 2,000 households) in the Indian state of Uttar Pradesh, with a treatment consisting of an informational campaign about the costs and procedure of applying. We found that households exposed to the campaign were three times as likely to apply for a connection. Yet actual connection rates remained unchanged. The results suggest that transaction costs are an important barrier to electrification, but limited capacity and incentive to expand connections are equally important.
\end{abstract}

\footnotetext{
${ }^{*}$ We would like to thank the University of Houston's Hobby School of Public Affairs for support. Replication files are available at https://doi.org/10.7910/DVN/KYQSY8.
} 


\section{Introduction}

The United Nations Sustainable Development Goal (SDG) 7 seeks to "ensure access to affordable, reliable, sustainable and modern energy." The first target within SDG 7 is to achieve universal electrification by the year 2030. Many studies suggest that such expansion would increase socioeconomic development, productivity, and employment (Kanagawa and Nakata, 2008; Dinkelman, 2011; Lipscomb, Mobarak, and Barilam, 2013). To date, however, there is little empirical evidence as to the conditions under which efforts to expand electrification rates are more or less effective, short of simply raising income levels and pouring resources into connection drives.

The obstacles to electrifying rural households are manifold, and include not only their remoteness (Oda and Tsujita, 2011; Sankhyayan and Dasgupta, 2019), but also issues of affordability (Alkon, Harish, and Urpelainen, 2016) and poor service quality (Aklin et al., 2016). While these problems are structural and difficult to solve (McRae, 2015), an understudied and directly manipulable barrier stems from transaction costs. To apply for an electricity connection, households must understand the procedure, obtain information on the costs of the connection, and find the time and resources to physically complete and deliver their applications. These activities are timeconsuming, particularly for households with little formal education. Recently, the government of India attempted to overcome these obstacles with its "Saubhagya" initiative, launched in September 2017, which aimed to electrify all households by December 2018. To this end, it dedicated 2.5 billion dollars to provide (i) free or heavily subsidized connections and (ii) electrification camps that help households submit connection applications (see Supplementary Information Section A2) (Ministry of Power, 2017). How effective are these interventions in reducing transaction costs, and in actually increasing household electrification?

Here we report results from a preregistered randomized controlled trial in rural India to reduce the transaction costs of household electrification. In January 2018, we conducted a survey of 2,000 non-electrified households in the state of Uttar Pradesh, half of which participated in an electrifi- 
cation campaign. Participating households received a tutorial explaining the procedure and costs of applying for a connection, and were also offered transportation to deliver their applications. In this way, our campaign intervention is similar to that of the Saubhagya initiative, although our implementation preceded the Saubhagya camps. Thus, our findings allow us to provisionally test the effectiveness of such a campaign. We find that $27 \%$ of households exposed to our electrification campaign applied for electricity connections (confidence intervals 22.8\%-31.2\%), compared to nine percent in the control group (confidence intervals $6.2 \%-11.8 \%$ ). The electrification campaign successfully reduced informational barriers and transaction costs, with treated households indicating that they perceived the costs and difficulty of applying for a connection as lower than households in the control group. However, there was no difference in the rates at which treated and control households actually received connections. That is, even though over $27 \%$ of households in the treatment group applied for connections compared to just under $9 \%$ of households in the control group, only $2.8 \%$ (confidence intervals $1.6-4.1 \%$ ) and $2.7 \%$ (confidence intervals $1.4-4.1 \%$ ) of households in these two groups actually received connections, respectively. Thus, while our findings confirm that transaction costs are a formidable barrier to raising electrification rates, they also highlight that insufficient implementation capacity is another major obstacle, as utilities were either unwilling or unable to act on the applications they received. The core implication of this research, then, is that a balanced approach to electrification entails both improving information and investing in implementation capacity.

\section{Obstacles to Household Electrification in Uttar Pradesh}

In the Indian state of Uttar Pradesh (UP), once a household has applied for a connection, that application is then process by one of the state's distribution companies (discoms). Although electricity policy, including tariff rates, is determined at the state level, applications themselves are processed at the district level, and thus depending on the area of the state they are unlikely to make it to the capital of Lucknow (Sharma, Moerenhout, and Garg, 2018). Once an application has been pro- 
cessed, the discom is then tasked with providing the household with a connection to the nearest power pole, provided that it is within 40 meters of the household.

Numerous barriers prevent households from obtaining electricity connections, however. Some of these are outside their control, such as corruption or capacity issues in the discom, as well as poor service quality and geographical remoteness. Others stem from households' overall economic situations; some households may simply lack the disposable income to pay. Yet other obstacles, however, can be immediately overcome, such as lack of awareness of the application process and requirements.

First, households may lack the funds to pay for a connection. Because households face both an upfront cost to acquire a connection and monthly costs to maintain access (Haanyika, 2006; Alkon, Harish, and Urpelainen, 2016), even those that can afford connections be unable to afford the monthly fee. Alternatively, households may be unwilling to spend less on other goods to gain access to the grid (Khandker, Barnes, and Samad, 2012). Existing evidence suggests that popular support for lower prices is a formidable barrier to the pricing reforms that would otherwise be necessary to finance improvements in service (Aklin et al., 2014; Santhakumar, 2008; Blankenship, Wong, and Urpelainen, 2019).

Second, households may be unwilling to pay for an electricity connection because the quality is poor. Based on data from the 2017-2018 ACCESS survey, rural households in Uttar Pradesh had a median of 12 hours of daily service (Jain et al., 2018). Data from the Prayas Energy Group, which uses electricity supply monitors to directly track outages and voltage, similarly suggests that rural households in UP had just over 14 hours of daily service on average in $2018 .{ }^{1}$ Existing scholarship suggests that poor quality has a strong, negative effect on households' willingness to pay for electricity, as well as their satisfaction with their connections (Kemmler, 2007; Aklin et al., 2016; Graber et al., 2018; Kennedy, Mahajan, and Urpelainen, 2019). Poor service is related

\footnotetext{
${ }^{1}$ Daily average hours of supply in Uttar Pradesh, Electricity Supply Monitoring Initiative, Prayas Energy Group, https://www.watchyourpower.org/analysis_dashboard.php (accessed June 29, 2019).
} 
to capacity problems. Distribution companies may be unwilling or unable to extend connections and provide quality service. In the Indian context, tariffs set by the state regulators are at an artificially low rate below the full cost of service (Tongia, 2017). As a result, discoms provide electricity at a significant loss, owing to a combination of electricity theft, unpaid bills, and low tariffs embedding a cross-subsidy by other users (Chattopadhyay, 2004; Harish and Tongia, 2014; Golden and Min, 2012; Tongia, 2017). Moreover, due to their geographic remoteness, it is quite expensive to provide connections to many rural households (Oda and Tsujita, 2011; Sankhyayan and Dasgupta, 2019). Consequently, discoms may neglect the needs of rural consumers because they lack both the capacity and incentive to extend and improve service (McRae, 2015; Rains and Abraham, 2018).

Other obstacles, however, can be overcome more immediately. In particular, households face transaction costs to obtaining an electricity connection. To apply for a connection, households must not only know the process and cost of doing so, but also must be able to deliver their applications. A lack of knowledge of the process - as well as constraints on the resources and time needed to complete and deliver applications - may thus artificially suppress electrification rates, leaving latent demand for connections. A long line of literature in economics argues that transaction costs can impede efficient operating in the market (Coase, 1937; Williamson, 1981). These include search and information costs associated with the difficulty in determining the price of a good or service and discovering alternative goods and services; bargaining costs arising from the time and effort required to strike a deal; and policing and enforcement costs from the need to monitor that one's partner complies (North, 1990, 1992). Indeed, evidence suggests that these electrification transaction costs are substantial in rural Uttar Pradesh. Our baseline survey of 2,000 households showed that $77 \%$ of households did not know the cost of a connection, and our pilot found a lack of awareness of the procedure and overestimation of the application cost.

Thus, we designed an intervention to directly reduce search and information costs and alleviate the burden of completing and delivering applications. Specifically, our treatment works through 
two mechanisms. First, it increases participants' knowledge of the costs and procedure of applying. Second, it makes delivering applications easier by offering to collect and submit applications on respondents' behalf. Ultimately, our results shed light on the relative importance of these obstacles to households electrification: affordability, quality, implementation capacity, and transaction costs.

\section{Research Design}

In order to test whether reducing transaction costs could result in an increase in electrification rates, we conducted a randomized controlled trial in rural Uttar Pradesh. ${ }^{2}$ Our experiment took place during the month of January 2018 in the Sitapur and Bahraich districts of UP, shown in Figure 1, which are located between 100 and $150 \mathrm{~km}$ from the regional capital of Lucknow, making them accessible to our numerators, but not so close to the regional capital that this would confound our results. Both districts are predominately rural, $11.8 \%$ and $5 \%$ respectively. And they have literacy rates of $61 \%$ and $51.1 \%$, a little below the average for Uttar Pradesh as a whole (67.68\%), but reasonably consistent with rates in other rural areas of the state. Because both districts generally have an adequate supply of electricity but low connection rates, the electrification profile works well for the purposes of our study. The campaigns and surveys were conducted by Morsel India, a survey and analytics firm based in Lucknow. Before the treatment was administered, we conducted a baseline survey of all households (both treatment and control) in the sample, and we then conducted an endline survey three months later in April 2018.

[Figure 1 about here.]

Notably, our treatment preceded the rollout of the government-run camps in the Sitapur and Bahraich districts as part of the Saubhagya scheme. Moreover, only 2 out of the 2,000 participants in the study had heard of Saubhagya. It also proceeds the widespread rollout in Uttar Pradesh more generally, that occurred at the beginning of $2019 .{ }^{3}$ This increases our confidence that it was

\footnotetext{
${ }^{2}$ Data and code used to conduct the analysis will be made available on the Harvard Dataverse.

${ }^{3}$ https: //saubhagya.gov.in/
} 
our intervention, rather than government outreach, that accounts for any changes in the outcome variable between the baseline and endline surveys.

\subsection{Treatment: Electrification Campaign}

In the intervention, we provided a brief tutorial on the requirements and costs of applying for an electricity connection, and offered to provide transportation to deliver applications. Treatment was assigned to households on the basis of their habitation, which was identified in advance by one Morsel enumerator. ${ }^{4}$ Because households were recruited prior to the assignment of treatment, enumerators used the same recruiting language to recruit participants in treated and non-treated habitations. Potential participants were not told about the procedure or cost of receiving a connection prior to the treatment's initial administration (i.e., provision of application), and the control group was not provided this information at all). ${ }^{5}$ One thousand households, spread evenly across 100 habitations in our sample, were randomly assigned to participate in the electrification campaign, while an equal number of households and habitations composed the control group. In order to be included in the sample, households could not have a grid electricity connection but needed to reside in an electrified habitation. The balance tests shown in Figure 2 indicate that our treatment and control groups were balanced across a range of covariates, suggesting that our randomization procedure was successful.

[Figure 2 about here.]

Following the baseline survey, which was administered in treated and untreated habitations, the electrification campaign in treated habitations consisted of the following steps, undertaken individually with each participating household. First, those in the treatment condition were given

\footnotetext{
${ }^{4}$ In India, habitations are sub-village administrative units used for tracking economic and educational outcomes. Multiple habitations are usually served by a feeder.

${ }^{5}$ It should be noted that all respondents were asked whether they had heard of the Saubhagya scheme. While it is possible that this could constitute a weak treatment insofar as by bringing this to people's attention, we encourage information searching, it is unlikely that this affected our results. For one, this would have affected both treatment and control groups. Moreover, if posing this question did have an effect, then it was clearly overwhelmed by the effect of the tutorial.
} 
a detailed introduction to electricity application, its cost, the associated procedure and timeline, and the support offered. Information provided during this introductory meeting is tailored to the household (e.g. only Below Poverty Line (BPL) households, who are provided with free electricity connections, are told BPL requirements). ${ }^{6}$

Second, treated participants were reminded that all new connections are metered and that the fixed meter rent is 50 rupees per month. Third, treated participants were provided with three-page cheat sheets that summarize relevant information and requirements. Fourth, treatment participants were also shown pictures of necessary application materials to obtain an electrical connection: an application form, photos, housing information, identification (BPL if appropriate), and payment. Fifth, participants decided whether to submit an application for an electrical connection. Finally, participants filled out a survey about the electrification campaign and the usefulness of the information provided.

Following the electrification campaign, enumerators engaged in phone calls with households who chose to submit an application to ensure its timely preparation and associated payment. The enumerators and participants also agreed to a date (no later than two weeks after the baseline survey was administered) on which the enumerators could pick up the application. Prior to and during the baseline survey, enumerators were in contact with discom employees in order to ensure that the the applications could be collected and processed. After conferring with the applicant about when they could expect their applications, an enumerator contacted the discom's local power house to remind them about the experiment and to inform them that the enumerators would collect the applications. On the date agreed upon by the enumerator and applicant, the enumerator visited each habitation to collect application materials, which were taken to the power house. ${ }^{7}$ For each house-

\footnotetext{
${ }^{6}$ BPL households are defined according to the 2011 Socio Economic and Caste Census (SECC). Whether a household qualifies as BPL is based on an index system that takes into account items like household possessions, deprivation, and occupation. Seventy-two percent of our respondents had BPL ration cards, including seventy-five percent in the treatment condition and sixty-nine percent in the control condition. The balance tests in Figure 2 show that this difference is not statistically significant.

${ }^{7}$ In some cases, an employee of the power house accompanied the enumerator to help collect the applications and payments.
} 
hold, enumerators recorded whether the application was successfully submitted. ${ }^{8}$ At the time of the treatment, treated households were asked if they would be interested in submitting an application. If they indicated that they would be, enumerators followed up with them within two weeks to pick up applications. Respondents who originally said they would be interested in applying were not obligated to provide an application to enumerators or to apply at all. Enumerators only followed up with those respondents who said they would submit. Respondents who did not show interest in submitting were not further contacted by enumerators until the endline survey.

A potential effect arising from the implementation of an electrification campaign is the increased salience of government or utility (in)action to the participating respondents. For the treated households, we provide assistance to apply for electricity connections; should these connections not realize in a timely manner, there may be negative feelings towards the government or the regional discom. We worked with local officials to make sure that all the procedures were followed, and made sure to work with the local electricity companies to ensure that everything was received in good order. The applications are then subjected to the usual procedures.

\subsection{Outcome Variables}

We measured four main outcome variables in an endline survey, conducted in late April-May 2018, three months after the treatment: whether the household applied for a connection, whether it received a connection, respondents' perceptions of the ease of applying, and respondents' perceptions of the affordability of applying.

\subsection{Control Variables}

In the baseline survey we asked a number of additional items that serve as control variables. In particular, we asked respondents about their perception about their own household's economic

\footnotetext{
${ }^{8}$ One may be concerned that the role of enumerators could affect the treatment by introducing idiosyncratic factors such as the skills, abilities, and motivation of particular enumerators. To guard against this, we run the main results after including enumerator fixed effects; see Table A8. Moreover, none of the enumerator dummies have a statistically significant effect on our outcome variables.
} 
situation, as well as whether they have a ration card. ${ }^{9}$ In the pre-analysis plan we also indicated that we would control for whether households had heard of the Saubhagya scheme, as well as their pre-treatment estimates of the cost of applying for a connection. However, only 2 of 2,000 respondents knew what Saubhagya was, and thus there is essentially no variation. Additionally, $76.6 \%$ of households did not know how much the cost of a connection was, and thus including this variable causes us to lose the vast majority of our observations.

\subsection{Model Specification}

The specification equation for testing the effect of the electrification campaign on our outcomes is an ordinary least squares model specified as follows:

$$
Y_{i j}=\alpha+\beta_{1} \text { Campaign }_{j}+\gamma \mathbf{X}_{i j}+\zeta \mathbf{Z}_{k}+\epsilon_{i j}
$$

where $Y_{i j}$ is the indicator for one of our outcome variables, Campaign is a dummy indicator for whether habitation $j$ participated in an electrification campaign, $\mathbf{X}$ is a vector of control variables, and $\mathbf{Z}$ is a vector of fixed effects by electricity feeder $k{ }^{10}$ We estimate robust standard errors clustered by habitation.

To understand the underlying causal mechanisms, we test whether households who perceived the electrification campaign to be the most effective were also the households who were most likely to agree to submit an application in the next two weeks after the treatment was administered. In particular, we measure several characteristics related to the tutorial: their overall satisfaction with

\footnotetext{
${ }^{9}$ Households were given options to indicate that they did not have a ration card, had a BPL ration card, or an APL ration card. With respect to their own economic situation, households indicated that they are "struggling to pay expenses" (coded as 1), "able to pay for current expenses, but not able to put money away for future" (2), and "can pay current expenses and [are] able to put away some money for future expenses" (3).

${ }^{10}$ Feeders are the link between the electricity sub-station responsible for power distribution and the consumers. Feeders thus serve as conduits in the distribution process between electricity transmission and neighborhoods, and consumers of the same feeder thus share similarities in terms of the quality of their power supply. Indeed, in many cases, the government cuts supply at some feeders when demand outstrips supply, containing the impact in order to avoid a wider blackout. Within each habitation in our sample, each all residents were served by the same feeder. Our sample included seven separate feeders, some of which served as many as 45 of the 200 habitations in our sample, others of which served as few as 7 .
} 
the tutorial, how much they learned in the tutorial, and the extent to which they felt their questions were answered. We also controlled for their rating of the ease of gaining electricity access, their rating of the affordability of the application process, and their perceptions of their own economic situations.

Agreeing to submit an application within two weeks is modeled as:

$$
Y_{i j}=\alpha+\beta_{1} \text { Satisfaction }_{i}+\beta_{2} \text { Learned }_{i}+\beta_{3} \text { Answered }_{i}+\gamma \mathbf{X}_{i j}+\zeta \mathbf{Z}_{k}+\epsilon_{i j}
$$

where $Y_{i j}$ is the indicator for whether household $i$ in habitation $j$ wants to submit an application in the next two weeks and $\alpha$ overall intercept, Satisfaction is the measure of how satisfied each respondent was with the tutorial, Learned is a self-reported measure of how much each respondent learned from the tutorial, Answered is the measure of the extent to which respondents felt they had their questions answered, $X_{i j}$ is a vector of control variables, and $\mathbf{Z}$ is a vector of fixed effects by feeder $k . \epsilon_{i j}$ is the error term.

Finally, as described in the pre-analysis plan, we also considered potential heterogeneous treatment effects on primary outcomes based on the level of individual trust. Previous literature suggests that trust is a strong determinant of willingness to pay for electricity in rural Uttar Pradesh, as trust can assuage potential concerns that the utility company will not follow through on its promises or that others in the community will not overburden the system and drive down supply quality by stealing electricity (Blankenship, Wong, and Urpelainen, 2019). Households were asked their degree of trust in the state government, the utility company, the pradhan, and their neighbors. Responses, measured on a scale from 1 ("strongly distrust") to 5 ("strongly trust"), were then combined using a standard Likert Scale to produce an index of trust. We expect that high trust individuals are more willing to trust our enumerators to submit their applications and the government to follow through, and thus more likely to apply for and receive connections. To test 
this conjecture, we consider estimated coefficients of the following specification

$$
Y_{i j}=\alpha+\beta_{1} \text { Campaign }_{j}+\beta_{2} \text { Trust }_{i j}+\beta_{3}\left(\text { Campaign }_{j} * \text { Trust }_{i j}\right)+\gamma \mathbf{X}_{i j}+\zeta \mathbf{Z}_{k}+\epsilon_{i j}
$$

which adds an indicator Trust ${ }_{i j}$, describing the household's trust index, to the specification given in equation 1. In all models, we estimate robust standard errors clustered by habitation.

\section{Results}

The main findings are shown in Figure 3. These results come from eight ordinary least squares regression models - two per dependent variable - all of which include feeder fixed effects, and half of which include control variables. ${ }^{11}$

Households exposed to the electrification campaign applied for connections at a rate almost twenty percentage points higher than that of the control group (27.2\% versus $8.6 \%)$. Similarly, treated households found applying for a connection less difficult and costly than those that did not participate in the campaign. At the same time, however, treated households did not have higher electrification rates. This result is troubling, suggesting that a three-fold increase in applications produced almost no impact on actual electrification. While awareness poses a substantial obstacle to electrification, further barriers remain.

[Figure 3 about here.]

We subjected the results to a number of robustness tests as well. First, in Supplementary Table A6, we use alternative model specifications. Although we use ordinary least squares models throughout our main alaysis, two of our outcome variables (whether respondents applied for and received connections) are dummy variables, while the other two (perceived ease/affordability of applications) are ordinal variables. Thus, as a robustness check we instead use logit and ordered logit models for these sets of outcome variables, respectively. Our original findings remain intact.

\footnotetext{
${ }^{11}$ All results can be found in table form in Supplementary Information Section A3.
} 
Households participating in the campaign had about $307 \%$ (or more than three times) higher odds of applying for a connection, and about $75 \%$ higher odds of perceiving greater ease and affordability of applying, when compared to households in the control group. Second, because we have a number of missing observations in two of our outcome variables - perceived ease and affordability of application - we created an imputed dataset. Supplementary Table A10 shows the results, which are consistent with the main results.

In Figure 4 and Supplementary Table A14, we explore causal mechanisms. After the treatment was administered, we asked all treated households about their experience with the tutorial, namely: (1) how satisfied they were with the tutorial; (2) how much they learned from the tutorial; (3) the extent to which they felt they had their questions answered by the tutorial. We also asked them how easy and how affordable they perceived applying for a connection to be. We expected that treated households who expressed greater satisfaction with the tutorial and who learned the most from the campaign would be more likely to apply for a connection. The results are consistent with these expectations. Households indicating (i) higher levels of satisfaction with the campaign and (ii) that they had their questions answered in the tutorial were more likely to agree to apply for a connection. Similarly, households reporting that they learned more from the campaign were more likely to apply, though this effect is not quite statistically significant at the 0.05 level (two-tailed test). ${ }^{12}$ Although these results are not conclusive, they suggest that the respondents who benefited the most from the tutorial were most likely to apply for connections. Moreover, respondents' perceived ease of applying was a better predictor of their decision to apply than their perceived

\footnotetext{
${ }^{12}$ In addition to considering differential effects associated with subjects' self-reported learning, we also consider differences on the basis of subjects' estimates of connection costs, measured in the baseline questionnaire. Given the prevalence of households reporting that they did not know the connection costs $(77 \%)$ and the inaccuracy of estimated connection costs - on average, APL households over- or underestimated connection costs by 1200 rupees, and BPL households by 894 rupees - it is unclear how meaningful the differences are between respondents who said they did not know and those who gave a numerical estimate. As shown in Supplementary Table A17, there does not appear to be evidence suggesting differential effects of the campaign among households on the basis of self-reported knowledge of connection costs. The true costs of connection was known for households with ration cards, and among those that provided estimates, we measured the inaccuracy of their prior beliefs using the absolute value of the difference between the estimates and the true costs. Supplementary Table A18, provides limited evidence for differences in the campaign effect on the basis of the inaccuracy of household beliefs.
} 
affordability, suggesting that transaction costs pose a substantial barrier to electrification even when compared to cost.

[Figure 4 about here.]

Finally, in Supplementary Figure A1, we estimate heterogeneous treatment effects, as specified in the pre-analysis plan. We expected that households' self-reported trust in others would condition the effect of the treatment, with more trusting participants exhibiting a greater response to the treatment. Here the results are weak. The interaction term between the campaign and trust is not statistically significant, and the marginal effects reported in Supplementary Figure A2 show that the confidence intervals for the effect of the treatment at each level of trust overlap entirely. The substantive effects, however, are fairly large; among households reporting the lowest levels of trust, the campaign had essentially no effect, while among those with high trust, the campaign increased application rates by 20 percentage points.

Taken together, our results indicate that the campaign successfully reduced households' transaction costs of applying for connections. Nevertheless, connection rates showed no significant increase among treated households, producing a substantial gap between applications and actual connections. Our data only allow us to speculate about the cause of this gap, but three related possibilities stand out. The first is a lack of implementation capacity. Discoms, for instance, may have failed to secure necessary resources to process all submitted applications and, as pointed out by skeptics of the Saubhagya scheme, such shortfalls in capacity may hinder implementation (Rains and Abraham, 2018; Singh, 2017) ${ }^{13}$. Second, the discoms may be forestalling service extension to avoid providing electricity to more households at an artificially low rate (Tongia, 2017). Third, implementation capacity may be linked with Saubhagya anticipation, whereby resources were not

\footnotetext{
${ }^{13}$ The implementation of the Saubhagya scheme accelerated after our field study, where connection realizations eventually took place. In Uttar Pradesh, the most rapid phase of electrification was reported to be from August to December of 2018, which is several months after the study period. To date, full electrification has been reported according to the Saubhagya scheme's official website. Thus we have confidence that the delay in connection delivery is associated with capacity constraints, which was eventually overcome albeit several months later.
} 
mobilized prior to or were tied to the actual state-directed intervention, so electrification rates stagnated despite increases in applications.

\section{Conclusion and Policy Implications}

This study sought to determine whether an informational campaign could increase electrification rates in rural India. We implemented a randomized controlled trial in which half of our households participated in such a campaign. Our results show that the campaign decreased transaction costs associated with applying for connections by increasing awareness of the procedure and associated costs, thus lowering households' perceptions of the difficulty and cost of applying and, in turn, increasing their application rates. Nevertheless, these applications did not significantly increase connection rates among treated households, suggesting that formidable barriers to electrification remained.

The theoretical implications of these results are clear. Transaction costs are a major barrier to expanding electrification, but they are not the only or even necessarily the most important obstacle. Shortages in implementation capacity - namely, the discom's ability to both process new applications and act upon them - appear to be a crucial barrier. Perhaps equally important is the discom's lack of incentive to process new applications, as each new connection imposes a financial loss (Tongia, 2017; Chattopadhyay, 2004; Harish and Tongia, 2014).

From a policy perspective, the findings suggest that informational campaigns are necessary but insufficient. Households are unlikely to apply for connections unless the transaction barriers preventing them from understanding the procedure and costs of applying are reduced. Tackling the issue of implementation capacity is essential to convert applications into connections. Indeed, our findings may help explain why - notwithstanding government claims of $100 \%$ rural household electrification in the wake of Saubhagya ${ }^{14}$ - there is evidence that many households still remain without connections, since these transaction costs increase the number of people who say they do

\footnotetext{
${ }^{14}$ Ministry of Power, "Saubaghya Dashboard," http://saubhagya.gov.in/ (accessed June 30, 2019).
} 
not want connections; even with the intervention, about $70 \%$ decided not to apply (Urpelainen, 2019)..$^{15}$

That said, the implementation of the Saubhagya scheme after our experiment did result in a rapid expansion of electricity connections in the study districts. This success highlights the importance of implementation. Simply encouraging households to apply was not enough without investing in implementation capacity. When government agencies added a robust implementation strategy, concrete results followed.

To replicate such success elsewhere, governments across the world could pursue several strategies. First, they could increase electricity prices, though this approach is fraught with political costs and may raise a new affordability barrier. Indeed, a recent study found that on average, households are only willing to pay about 40 extra rupees per month in exchange for four additional hours of service a day, suggesting that affordability remains a major hurdle (Blankenship, Wong, and Urpelainen, 2019). Second, the government could simply dispense with the application process altogether, and instead provide connections unless households opt out. This may, however, engender opposition from discoms who incur losses from offering connections to uninterested households. Third, the government could make extensions in service more palatable by providing incentives to discoms. Indeed, in October 2018 the Indian government announced a reward system for discoms (Ministry of Power, 2018). Finally, distributed power generation such as solar home systems may offer basic energy access to low-demand households without further stress on power sector finances. If discoms are able to focus more on providing service to households that are willing to pay higher rates, they can improve their fiscal situations and launch a "virtuous cycle," wherein higher payments allow the discom to improve service, which in turn makes other consumers will-

\footnotetext{
15“India to achieve universal household electrification by January-end," The Economic Times, January 20, 2019, https://economictimes.indiatimes.com/industry/energy/power/india-to-achieve-universal-householdelectrification-by-january-end/articleshow/67609166.cms?from=mdr (accessed June 30, 2019); Peter Fairley, "A Power Line to Every Home: India Closes In on Universal Electrification," IEEE Spectrum, March 20, 2019, https://spectrum.ieee.org/energy/policy/a-power-line-to-every-home-india-closes-in-on-universal-electrification (accessed June 30, 2019).
} 
ing to pay higher prices. Off-grid solutions would thus put less pressure on a grid that already faces major funding constraints as a result of having to provide electricity at a financial loss to many households, thus giving discoms the opportunity to improve grid infrastructure and service quality (D'Cunha, 2018).

Future research might investigate whether similar campaigns could expand rates of access to alternative, off-grid sources of energy, such as solar power. These campaigns could be especially effective if accompanied with subsidies to producers or voucher to consumers. Alternatively, to focus more on grid connections, further investigation could identify the conditions under which households are willing to accept price increases. Recent research suggests that willingness to pay for price increases depends on a variety of factors, including both service quality and social trust (Blankenship, Wong, and Urpelainen, 2019; Kennedy, Mahajan, and Urpelainen, 2019), but future work could investigate whether specific interventions can increase willingness to pay. 


\section{References}

Aklin, Michaël, Chao-yo Cheng, Johannes Urpelainen, Karthik Ganesan, and Abhishek Jain. 2016. “Factors Affecting Household Satisfaction with Electricity Supply in Rural India." Nature Energy 1: 16170.

Aklin, Michaël, Patrick Bayer, S.P. Harish, and Johannes Urpelainen. 2014. "Information and Energy Policy Preferences: A Survey Experiment on Public Opinion about Electricity Pricing Reform in Rural India.” Economics of Governance 15 (4): 305-327.

Alkon, Meir, SP Harish, and Johannes Urpelainen. 2016. "Household Energy Access and Expenditure in Developing Countries: Evidence from India, 1987-2010.” Energy for Sustainable Development 35: 25-34.

Blankenship, Brian, Jason Chun Yu Wong, and Johannes Urpelainen. 2019. "Explaining willingness to pay for pricing reforms that improve electricity service in India.” Energy Policy 128: 459-469.

Chattopadhyay, Pradip. 2004. “Cross-Subsidy in Electricity Tariffs: Evidence from India.” Energy Policy 32 (5): 673-684.

Coase, Ronald. 1937. “The Nature of the Firm.” Economica 4 (16): 385-405.

D’Cunha, Suparna Dutt. 2018. “Modi Announces ‘100\% Village Electrification,' But 31 Million Indian Homes Are Still In The Dark.” Forbes.

Dinkelman, Taryn. 2011. "The Effects of Rural Electrification on Employment: New Evidence from South Africa.” American Economic Review 101 (7): 3078-3108.

Golden, Miriam, and Brian Min. 2012. “Theft and Loss of Electricity in an Indian State.” International Growth Centre Working Paper. 
Graber, Sachiko, Tara Narayanana, Jose Alfaro, and Debajit Palit. 2018. "Solar microgrids in rural India: Consumers' willingness to pay for attributes of electricity." Energy for Sustainable Development 42: 32-43.

Haanyika, Charles Moonga. 2006. "Rural electrification policy and institutional linkages.” Energy Policy 34 (17): 2977-2993.

Harish, Santosh M., and Rahul Tongia. 2014. "Do Rural Residential Electricity Consumers CrossSubside their Urban Counterparts? Exploring the Inequity in Supply in the Indian Power Sector.” Brookings India, Working Paper 04-2014.

Jain, Abhishek, Saurabh Tripathi, Sunil Mani, Sasmita Patnaik, Tauseef Shahidi, and Karthik Ganesan. 2018. "Access to Clean Cooking Energy and Electricity: Survey of States." Council on Energy, Environment, and Water report, November 2018.

Kanagawa, Makoto, and Toshihiko Nakata. 2008. "Assessment of access to electricity and the socio-economic impacts in rural areas of developing countries." Energy Policy 36: 2016-2029.

Kemmler, Andreas. 2007. "Factors influencing household access to electricity in India." Energy for Sustainable Development 11 (4): 13-20.

Kennedy, Ryan, Aseem Mahajan, and Johannes Urpelainen. 2019. "Quality of service predicts willingness to pay for household electricity connections in rural India.” Energy Policy 129: 319_ 326.

Khandker, Shahidur R., Douglas F. Barnes, and Hussain A. Samad. 2012. "Are the energy poor also income poor? Evidence from India.” Energy Policy 47: 1-12.

Lipscomb, Molly, A. Mushfiq Mobarak, and Tania Barilam. 2013. "Development Effects of Electrification: Evidence from the Topographic Placement of Hydropower Plants in Brazil." American Economic Journal: Applied Economics 5 (2): 200-231. 
McRae, Shaun. 2015. "Infrastructure Quality and the Subsidy Trap.” American Economic Review 105 (1): 35-66.

Ministry of Power. 2017. "Saubaghya Dashboard." http://saubhagya.gov.in/dashboard (accessed March 8, 2018).

Ministry of Power. 2018. "Shri RK Singh launches award scheme under 'Saubhagya'." Press Information Bureau, October 15, 2018.

URL: http://pib.nic.in/newsite/PrintRelease.aspx?relid=184197

North, Douglass C. 1990. Institutions, Institutional Change, and Economic Performance. New York: Cambridge University Press.

North, Douglass C. 1992. Transaction Costs, Institutions, and Economic Performance. San Francisco, CA: ICS Press.

Oda, Hisaya, and Yuko Tsujita. 2011. "The determinants of rural electrification: The case of Bihar, India.” Energy Policy 39: 3086-3095.

Rains, Emily, and Ronald J Abraham. 2018. "Rethinking barriers to electrification: Does government collection failure stunt public service provision?" Energy Policy 114: 288-300.

Sankhyayan, Pooja, and Shyamasree Dasgupta. 2019. “'Availability’ and/or 'Affordability’: What matters in household energy access in India?” Energy Policy 131: 131-143.

Santhakumar, V. 2008. Analysing Social Opposition to Reforms: The Electricity Sector in India. Thousand Oaks: Sage.

Sharma, Shruti, Tom Moerenhout, and Vibhuti Garg. 2018. "Electricity Sector Reform in Uttar Pradesh: Analysis of tariff adjustments and the Ujwal Discom Assurance Yojana Plan (UDAY)." Global Studies Initiative, March 2018. 
Singh, Sarita. 2017. "Saubhagya rollout may pose challenge: Ex-cabinet secy.”.

URL: https://economictimes.indiatimes.com/news/economy/policy/saubhagya-rollout-maypose-challenge-ex-cabinet-secy/articleshow/60861623.cms

Tongia, Rahul. 2017. “Can the Saubhagya scheme work?” The Brookings Institution.

URL: https://www.brookings.edu/opinions/can-the-saubhagya-scheme-work/

Urpelainen, Johannes. 2019. "Universal Rural Electrification in India? Not So Fast.” Power For All.

URL: https://www.powerforall.org/campaigns/india/universal-rural-electrification-india-notso-fast

Williamson, Oliver E. 1981. "The Economics of Organization: The Transaction Cost Approach." American Journal of Sociology 87 (3): 548-577. 


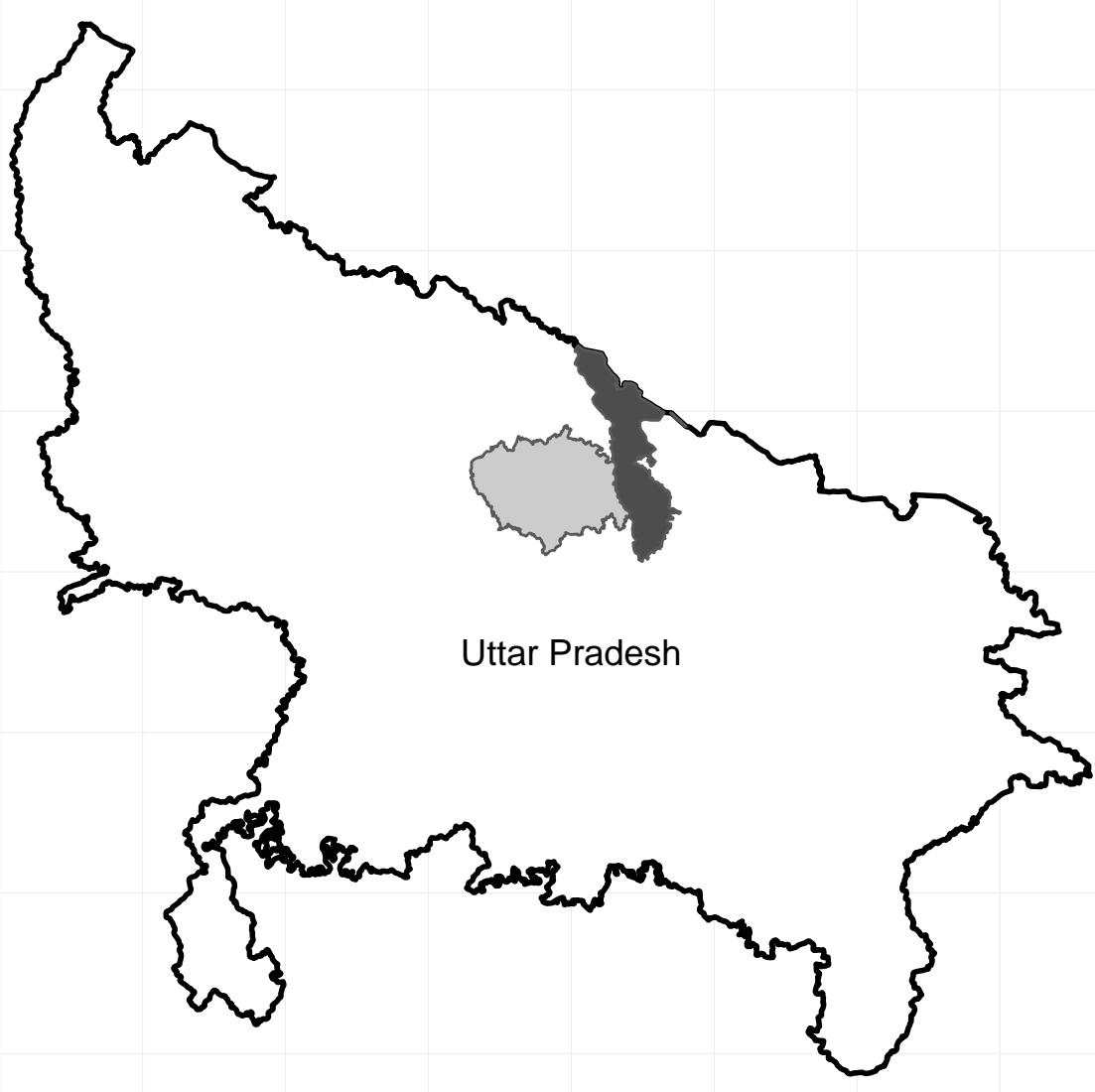

District $\square$ Bahraich $\square$ Sitapur

Figure 1: Bahraich and Sitapur districts in Uttar Pradesh, India, where the experiment was conducted. 


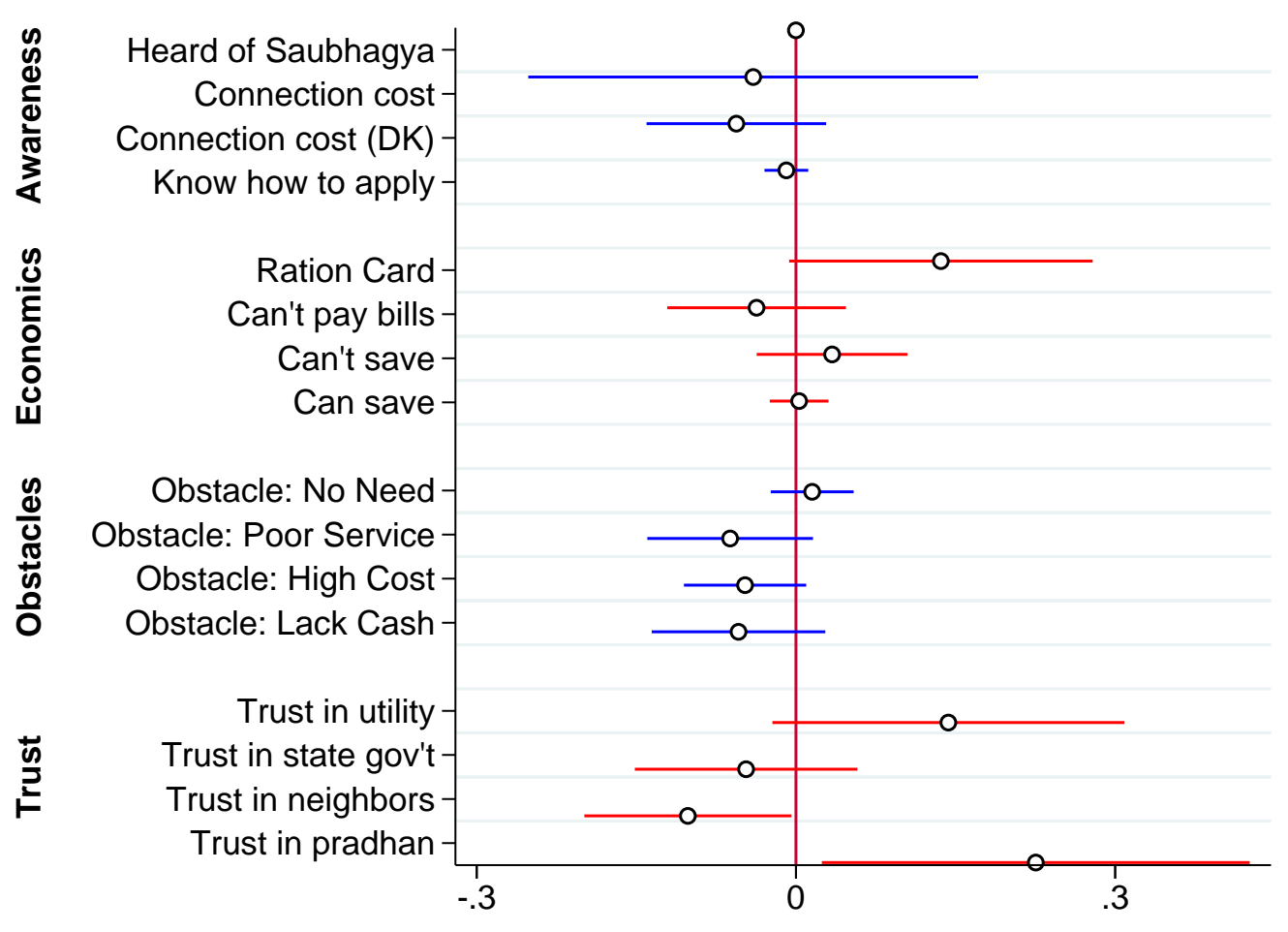

Figure 2: Balance diagnostics obtained by regressing baseline responses on assignment to treatment. The difference in means and associated confidence intervals, calculated using habitationclustered standard errors, suggest that randomization succeeded. "Connection cost" is in 1000s of rupees. Note that the coefficient for the "Heard of Saubhagya" variable is zero because only two respondents out of two thousand had heard of the scheme - one from the treatment group, one from the control group. 


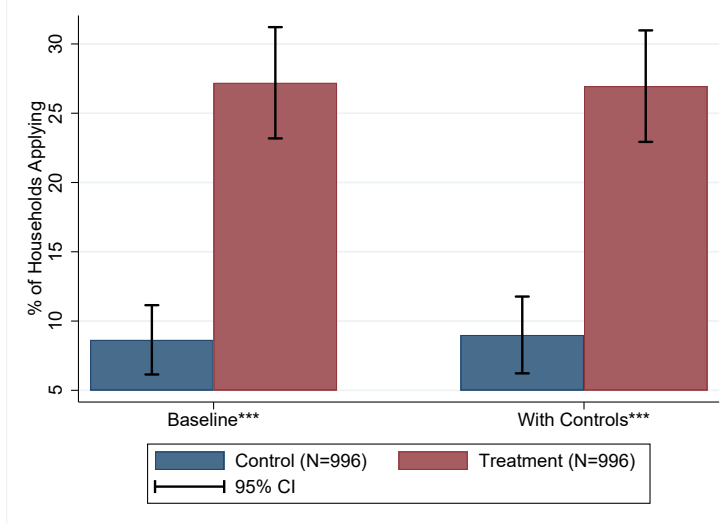

(a) Applying for a Connection

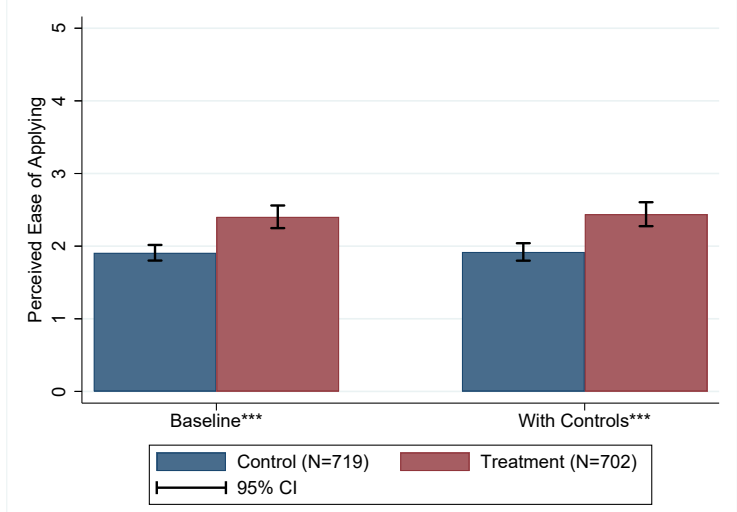

(c) Perceived Ease of Application

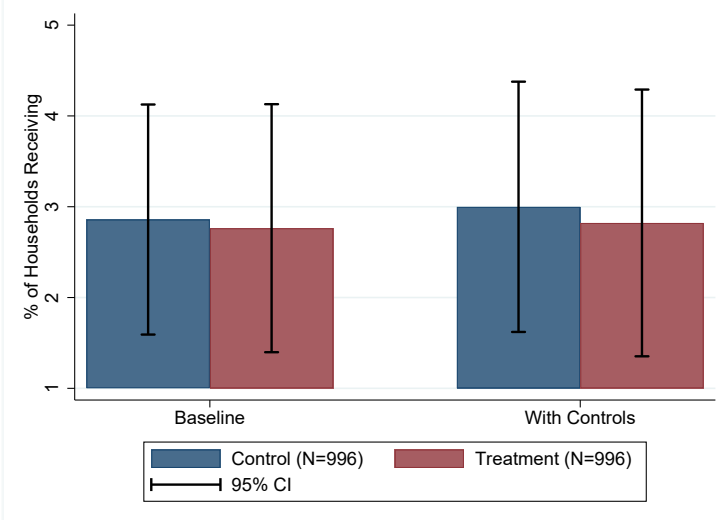

(b) Receiving a Connection

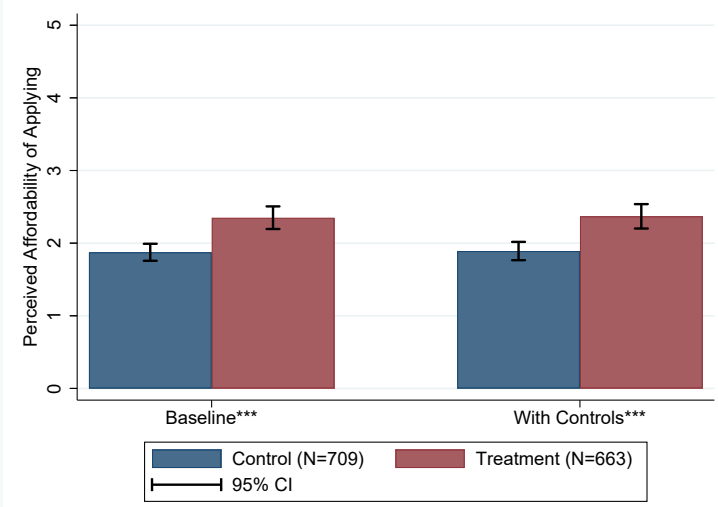

(d) Perceived Affordability of Application

Figure 3: Results showing the effects of participating in a campaign. Each subfigure contains both the results from a bivariate ordinary least squares regression (including feeder fixed effects) on the left, as well as the results after including additional control variables (the household's economic situation; the household's ration card status; and whether the household had heard of the Saubhagya scheme). The left (blue) bars within each set of results represents the control group mean, while the right (red) bars represents the treatment mean. Note that the number of observations are smaller in the models with control variables due to non-responses to some questions - namely that on ration cards. Moreover, we had a fairly large number of non-responses to the questions on perceived affordability and ease of application. Thus, we replicated our results using an imputed dataset to fill in the missing observations. The results are reported and described in Supplementary Information Section A3. 95\% confidence intervals are shown at the top of each bar. Standard errors are clustered by habitation. Statistical significance of difference between treatment and control means indicated by: ${ }^{*} p<0.05,{ }^{* *} p<0.01,{ }^{* * *} p<0.001$ 


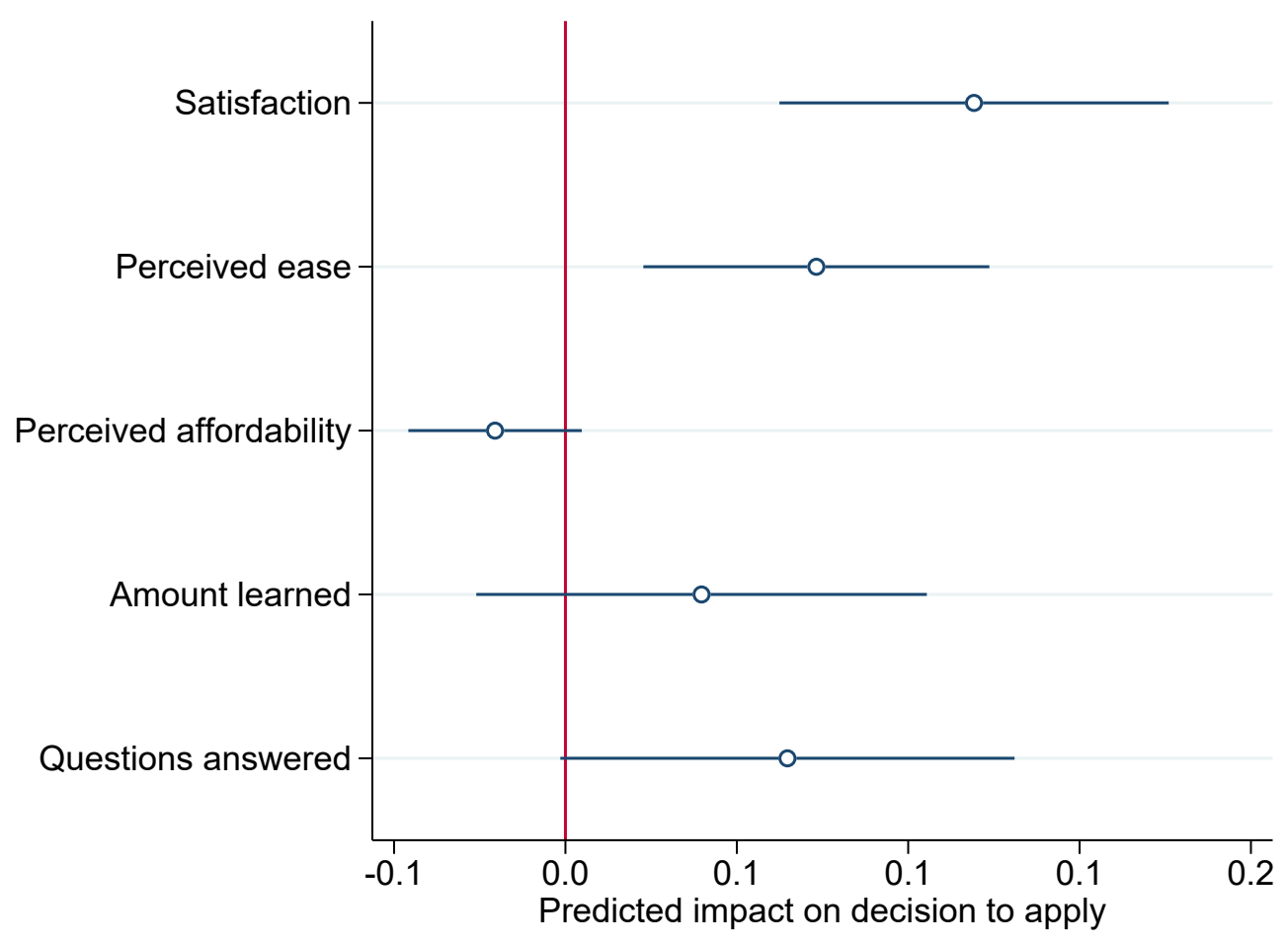

Figure 4: Results showing how the effectiveness of the electrification campaign contributed to respondents' decisions to apply for a connection $(N=1,000)$. Coefficients are calculated using a logistic regression model, and $95 \%$ confidence intervals are calculated using habitation-clustered standard errors. We asked all treated households about their satisfaction with the tutorial conveying information about applying for an electricity connection, and hypothesized that the treatment should be especially likely to lead to applications among households that learned a lot from the tutorial. Satisfaction refers to a question about treated respondents' satisfaction with the tutorial (1-5, where 1=Very Unsatisfied and 5=Very Satisfied), Perceived ease refers to a question about how easy respondents thought the process of applying was (1-5, where $1=$ Very difficult and 5=Very easy), Perceived affordability refers to a question about how affordable respondents thought applying for a connection (1-5, where 1=Very unaffordable and 5=Very affordable), Amount learned refers to a question about how much respondents thought they learned from the tutorial (1-5, where $1=$ Nothing and 5=A great deal), and Questions answered refers to a question about how much respondents felt they had their questions answered during the tutorial $(1-5$, where $1=$ Not at all and $5=\mathrm{A}$ great deal). 